\title{
Bibliometric analysis on the evolution of knowledge structure of African swine fever
}

\author{
Jee-Sun $\mathrm{Oh}^{1}$, Ho-Seong $\mathrm{Cho}^{2}$, Yeonsu $\mathrm{Oh}^{3 *}$ \\ ${ }^{1}$ School of Business and Technology Management, Korea Advanced Institute of Science and Technology, Daejeon 34141, Korea \\ ${ }^{2}$ College of Veterinary Medicine and Bio-Safety Research Institute, Jeonbuk National University, Iksan 54596, Korea \\ ${ }^{3}$ College of Veterinary Medicine and Institute of Veterinary Science, Kangwon National University, Chuncheon 24341, Korea
}

Received December 14, 2021

Revised December 25, 2021

Accepted December 25, 2021

\section{Corresponding author:}

Yeonsu Oh

E-mail: yeonoh@kangwon.ac.kr https://orcid.org/0000-0001-5743-5396

\begin{abstract}
Since African swine fever (ASF) spread to East Asia, a fatal crisis has occurred in the global pig industry, because Asia is dominant in pig production. Although some studies conducted bibliometric analysis on ASF, few studies compared research networks, and identified subthemes by major keywords. To fill this gap, this study identified the knowledge structure network of the research, its influence, and core research themes by utilizing the bibliometric analysis of 337 ASF-related journal articles over 50 years from 1970 to 2020 on the Web of Science. The result indicated that papers are mainly published in the fields of veterinary science, virology, microbiology, infectious disease and applied microbiology, and in particular, the fields of veterinary science and virology showed unrivaled weights as they account for $73.40 \%$. With regard to cooperative relationships, European countries such as the UK, Germany, Italy, and Denmark, centered on Spain, are actively contributing to the ASF research. China, France, Thailand, Japan, Vietnam, and South Korea are leading research cooperation, centering on the United States. In the early stage of the studies, major keywords appeared to be related to outbreaks, quarantine and diagnosis, and in the middle stage, the keywords were expanded to a wide range of pig diseases. Recently, the keywords are becoming more diverse towards antibodies, cross-border transmission and disease monitoring. Based on data on major keywords related to ASF, this study proposed discussions and implications for activating ASF research including genotype, protein, vaccine, diagnosis, defense against infection and epidemiological investigation.
\end{abstract}

Key Words: African swine fever, Bibliometric analysis, Global trend, Intellectual structure, Network analysis, Web of science

\section{INTRODUCTION}

African Swine Fever (ASF) is a fatal febrile hemorrhagic viral swine infectious disease that causes enormous economic losses (Costard et al, 2013; Penrith et al, 2013). It is a reportable disease to the World Organization for Animal Health (OIE) and is managed as a first-class livestock infectious disease in South Korea by Ministry of Agriculture, Food and Rural Affairs in 2018 (Kim et al, 2021). Since there are many dense pig farm complexes in South Korea, the spread of ASF can even lead to the collapse of the South Korean pig industry. ASF, which was an endemic disease in the African re- gion, is spreading around the world in modern times due to the development of transportation and logistics, and the factory like livestock industry based on the Concentrated Animal Feeding Operation (CAFO) (Brown et al, 2018). Therefore, each country is devoting all its might to rapid diagnosis, epidemiology, and effective quarantine toward ASF.

Understanding the trend and structure of researches that have been accumulated, is a major element in creating competitive advantages (Smith et al, 2005). Bibliometric analysis of literature on a certain theme is a useful tool for deepening understanding of overall research flow, evolution and core themes by identifying knowl- 
edge production, effect, collaboration and subthemes of research (Subramanyam, 1983). Among them, network analysis is valuable for constructing and clustering of collaboration, citation and influencing relationships among countries, authors, institutions and subjects to enhance visual understanding and identify research connectivity (Yan and Ding, 2012). Therefore, studies applying the reference methods and network analysis are increasing every year in many academic fields. In addition, such studies are helpful in understanding the rapidly changing evolution and dynamic state of knowledge, keywords emerging as core areas, and are useful in understanding the global knowledge structure and changes for promising technologies (Serenko et al, 2010). As such, understanding cooperation relationships in research fields or themes and analyzing the current situation are very important in terms of scientific quantification. In this study, knowledge structures and networking in the field of ASF were analyzed and compared.

ASF-related studies show largely three research trends (Table 1). The first trend is studies related to ASFV itself including genotypes, ASFV defense-related proteins, diagnosis, etc. (Gallardo et al, 2014; Malogolovkin et al, 2015; Sanna et al, 2017; Ge et al, 2018; Kim et al, 2020).

The second trend is studies on the occurrence, diagnosis, monitoring, and prevention of ASF by country (Śmietanka et al, 2016; Kolbasov et al, 2018; SánchezCordón et al, 2018; Wang et al, 2018; Zhou et al, 2018; Le et al, 2019; Dixon et al, 2020; Yoo et al, 2020).

The third trend is social science and policy studies related to the assessment of the social and economic impacts of ASF outbreak, social procedures for prevention of spreads, survey of the risk of the possibility of ASF spreads such as trade and smuggling, review of the current situation of outbreak and spreads, and social efforts for prevention (Gallardo et al, 2015; FernándezCarrión et al, 2016; Chenais et al, 2017; Guinat et al, 2017; Dixon et al, 2019; Jurado et al, 2019; Tian and von Cramon-Taubadel, 2020; Woonwong et al, 2020; Yoo et al, 2020).

There are some bibliometric studies in the field of pig disease studies. Those studies presented a research impact index or research production trends, but it is difficult to understand the overall field of ASF field due to the fragmentary quantitative analysis in the studies (Díaz et al, 2016; Andraud and Rose, 2020; Tian, 2020). Although some studies analyzed patterns through keyword analysis, the analysis of correlations between keywords is quite limited because it is impossible to identify related subthemes and keywords (Sinclair et al, 2020; Tian, 2020). There are limitations in understanding the overall research trends and themes of ASF studies, and there few studies explored and compared research cooperation and related indicators by major country, region, or institution.

Therefore, in order to bridge the gap with existing studies, this study analyzed knowledge structures and networks according to research trends and environments and identified hot spot research subthemes on ASF using bibliometric analysis and network analysis. In addition, sub-keywords of major keywords related to ASF were identified through bibliography and network analysis. In particular, this study seeks to answer

Table 1. Trends of studies related to ASF

\section{Trend}

1 Virus, detection, protein analysis, molecular characteristics, cytopathology

2 Cases of ASF occurrence, diagnosis, monitoring, quarantine, etc. by country

3 Policy approaches for social and economic impact of ASF outbreak, risk management, and disease control

\section{Previous study}

Kim et al, 2020; Malogolovkin et al, 2015; Sanna et al, 2017; Gallardo et al, 2014; Ge et al, 2018

Yoo et al, 2020; Zhou et al, 2018; Sánchez-Cordón et al, 2018; Le et al, 2019; Kolbasov et al, 2018; Dixon et al, 2020; Śmietanka et al, 2016; Wang et al, 2018 Yoo et al, 2020; Chenais et al, 2017; Jurado et al, 2019; Woonwong et al, 2020; Costard et al, 2009; Dixon et al, 2019; Fernández-Carrión et al, 2016; Tian and von Cramon-Taubadel, 2020; Guinat et al, 2017; Gallardo et al, 2015 
research questions including knowledge production, influence, collaboration, and core themes.

- RQ1: In which research fields, journals, countries, and institutions are knowledge production and influence on ASF research active?

- RQ2: Which countries and institutions are leading research cooperation, and what characteristics do the cooperation exhibit?

- RQ3: What were the main keywords and subthemes that led the related research? Is the evolution of keywords observed over time?

In this study, the global research flow in the field ASF was identified, and the current status of knowledge production, knowledge structures, and research cooperation relationships were analyzed. Based on the foregoing, the strengths and weaknesses of the studies were identified and implications for future ASF research were presented.

\section{SUBJECTS AND METHODS}

\section{Research framework and process}

In order to analyze the knowledge structure and core themes of ASF-related studies, the research process as shown in Fig. 1 was carried out. We selected the Web of Science database from among many academic databases that provide paper bibliographic information. The Web of Science is an academic bibliographic database covering a wide range of social sciences, humani- ties, natural sciences, engineering, and medicine, and is one of the most actively used databases in bibliometric analysis (http://www.webofknowledge.com). Preprocessing was performed, such as setting up a search formula with terms selected referring to related studies and expert opinions and purifying the collected bibliographic data.

Thereafter, basic statistical analysis was performed with research production information by research field, journal, country, region, institution, and keyword. Using the VOSViewer software, international cooperation structures and connection relations between keywords were analyzed. To analyze the connection relations between keywords, concurrence analysis and visual mapping were carried out, and clusters by keyword were organized. VOSviewer, a professional software that visually expresses scientific visualization with bibliographic data or text data, is widely used for bibliometric and network analyses (van Eck and Waltman, 2010).

\section{Data collection and data analysis}

Referring to existing studies on ASF or opinions of experts in the field of pig disease studies, search queries were set up to search for terms corresponding to titles, abstracts, and author keywords.

- Search formula: TS= ("African swine fever" OR "African swine fever*" OR "African swine fever virus pathogenesis" OR "pam cell” or "swine disease*”).

- Search period: A total of 50 years from 1970 to
Data retrieval and collection

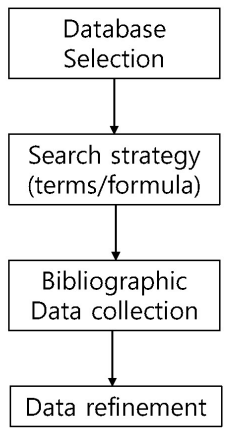

Bibliometric/network analysis

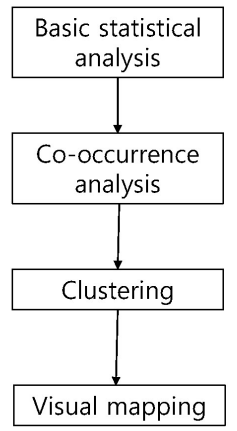

Result analysis

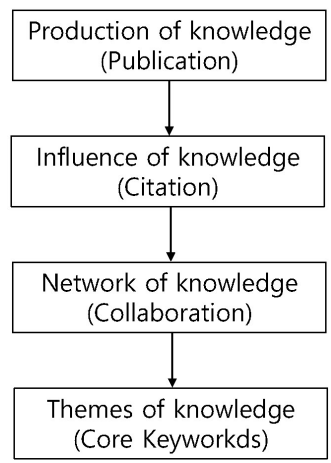

Fig. 1. Research framework. 
2020.

- Search target type: Article.

- Search Results: A total of 1,835 papers were retrieved (search performed on January 1, 2021).

\section{RESULTS}

\section{Overall publication}

In general, ASF-related papers have been steadily increasing. Fig. 1 shows the production of all papers. After three papers were produced in 1970, more than 40 papers were produced for the first time in 1992. After
83 papers were produced in 2015 and 108 papers were produced in 2017 while paper production was repeating the rise and fall, paper production explosively increased to 248 papers in 2020. As shown in Fig. 2A, the number times of citation of papers increased nearly twice from 1,462 in 2009 to 2,620 in 2013. The number of times of paper citation also showed a steady increasing trend similarly to paper production (Fig. 2B).

\section{Leading research field and journals in the ASF}

The top 20 fields in the field of ASF where the largest numbers of papers are produced, are shown in Table 2 .

(A)

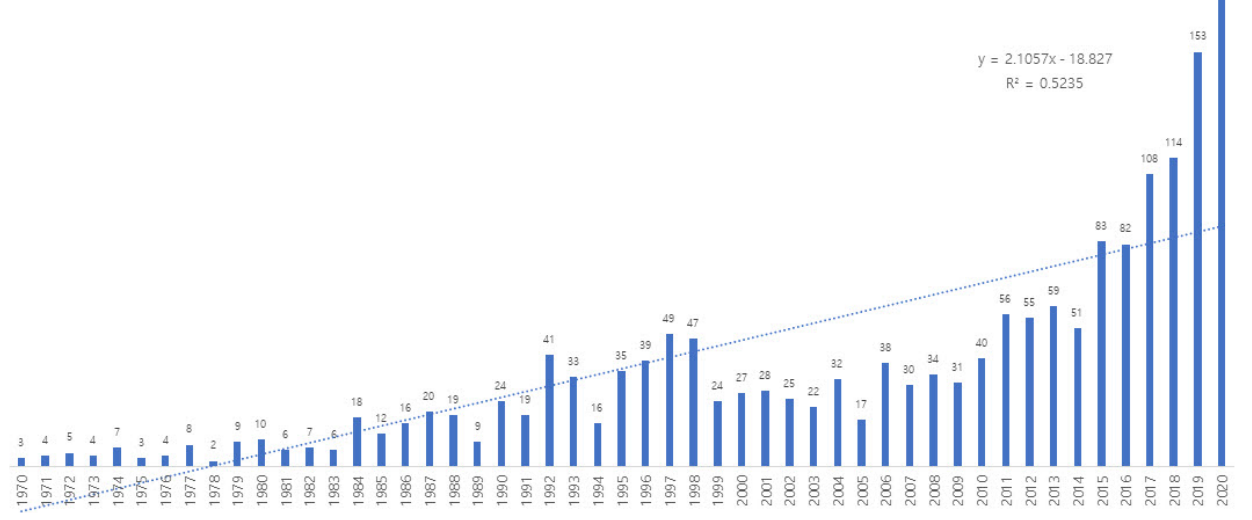

(B)

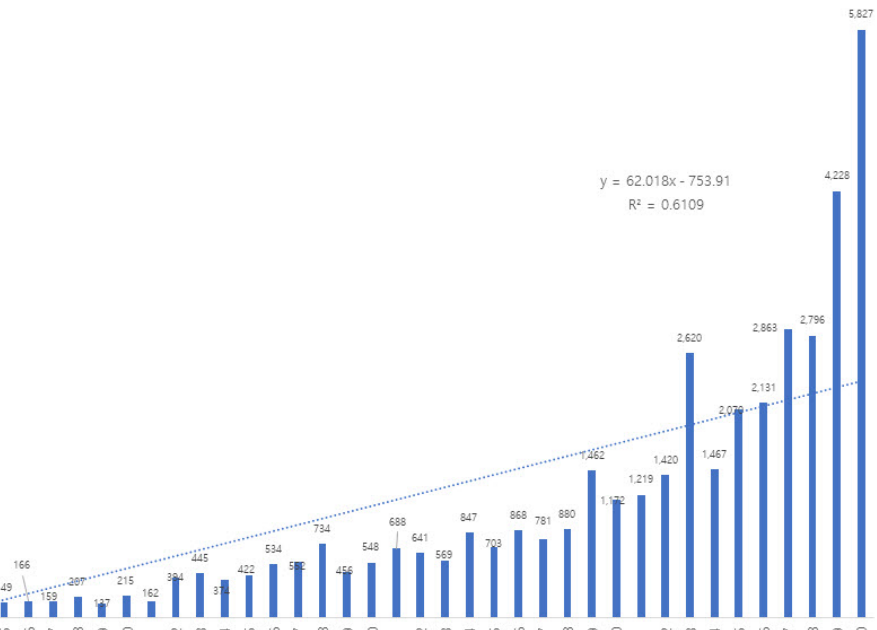

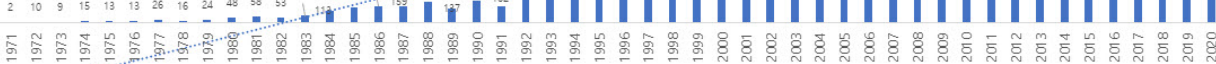

Fig. 2. (A) Distribution of publications by year. (B) Distribution of citations by year. 
Table 2. Leading research categories in publication and citation

\begin{tabular}{rlrc}
\hline Rank & \multicolumn{1}{c}{ Categories } & Documents & $\begin{array}{c}\text { Ratio } \\
(\%)\end{array}$ \\
\hline 1 & Veterinary sciences & 790 & 43.05 \\
2 & Virology & 557 & 30.35 \\
3 & Microbiology & 181 & 9.86 \\
4 & Infectious diseases & 172 & 9.37 \\
5 & Biotechnology applied microbiology & 149 & 8.12 \\
6 & Immunology & 117 & 6.38 \\
7 & Multidisciplinary sciences & 112 & 6.10 \\
8 & Biochemistry molecular biology & 79 & 4.31 \\
9 & Biochemical research methods & 66 & 3.60 \\
10 & Agriculture dairy animal science & 51 & 2.78 \\
11 & Parasitology & 43 & 2.34 \\
12 & Genetics heredity & 41 & 2.23 \\
13 & Pathology & 38 & 2.07 \\
14 & Medicine research experimental & 33 & 1.80 \\
15 & Cell biology & 31 & 1.69 \\
16 & Pharmacology pharmacy & 25 & 1.36 \\
17 & Food science technology & 24 & 1.31 \\
18 & Public environmental occupational & 21 & 1.14 \\
& health & & \\
19 & Analytical chemistry & 19 & 1.04 \\
20 & Entomology & 19 & 1.04 \\
\hline & & & \\
\hline
\end{tabular}

Source: Author's computation and elaboration with the WOS data.
Papers are mainly published in the fields of veterinary science, virology, microbiology, infectious diseases, and applied microbiology. In particular, the fields of veterinary science and virology account for $73.40 \%$ of the entire fields, which is an unrivaled proportion.

The top 20 journals in which the largest numbers of papers are published in the field of ASF, are shown in Table 3. For 50 years from 1970 to 2020, the Journal of Virology recorded number one with a total of 139 papers published in it. The second place was taken by transboundary and emerging diseases, third place by veterinary microbiology, fourth place by virology, and fifth place by archives of virology. Papers were published mainly in journals in the fields of cross-border transmission, virology, and microbiology.

The top 20 journals from which the largest numbers of papers were cited, and which are the most influential in the field of ASF, are shown in Table 4. A total of 139 papers were published in the Journal of Virology over 50 years from 1970 to 2020, and the total number times

Table 3. The most productive journal in the ASF research

\begin{tabular}{|c|c|c|c|c|c|}
\hline Rank & Categories & Documents & Ratio (\%) & Citations & IF \\
\hline 1 & Journal of Virology & 139 & 7.57 & 6,275 & 4.370 \\
\hline 2 & Transboundary and Emerging Diseases & 126 & 6.87 & 1,572 & 1.514 \\
\hline 3 & Veterinary Microbiology & 86 & 4.69 & 2,272 & 3.030 \\
\hline 4 & Virology & 73 & 3.98 & 2,905 & 2.819 \\
\hline 5 & Archives of Virology & 64 & 3.49 & 1,976 & 2.261 \\
\hline 5 & Journal of General Virology & 64 & 3.49 & 2,220 & 3.376 \\
\hline 7 & PLOS One & 57 & 3.11 & 1,386 & 2.740 \\
\hline 8 & Journal of Virological Methods & 51 & 2.78 & 1,152 & 1.746 \\
\hline 9 & Preventive Veterinary Medicine & 51 & 2.78 & 821 & 0.969 \\
\hline 10 & Virus Research & 42 & 2.29 & 841 & 2.736 \\
\hline 11 & American Journal of Veterinary Research & 35 & 1.91 & 992 & 1.140 \\
\hline 12 & Scientific Reports & 35 & 1.91 & 424 & 3.998 \\
\hline 13 & BMC Veterinary Research & 28 & 1.53 & 358 & 1.792 \\
\hline 14 & Veterinary Research & 28 & 1.53 & 713 & 1.792 \\
\hline 15 & Virus Genes & 27 & 1.47 & 722 & 1.51 \\
\hline 16 & Frontiers in Veterinary Science & 26 & 1.42 & 137 & 0.859 \\
\hline 16 & Viruses Basel & 26 & 1.42 & 99 & 3.816 \\
\hline 18 & Veterinary Immunology and Immunopathology & 25 & 1.36 & 614 & 1.846 \\
\hline 19 & Journal of Comparative Pathology & 24 & 1.31 & 597 & 1.100 \\
\hline 20 & Journal of Veterinary Diagnostic Investigation & 19 & 1.04 & 324 & 0.925 \\
\hline 20 & Virology Journal & 19 & 1.03 & 342 & 2.464 \\
\hline
\end{tabular}

Source: Author's computation and elaboration with the WOS data. 
Table 4. The most influential (cited) journal in the ASF research

\begin{tabular}{|c|c|c|c|}
\hline Rank & Categories & Citations & Documents \\
\hline 1 & Journal of Virology & 6,275 & 139 \\
\hline 2 & Virology & 2,905 & 73 \\
\hline 3 & Veterinary Microbiology & 2,272 & 86 \\
\hline 4 & Journal of General Virology & 2,220 & 63 \\
\hline 5 & Archives of Virology & 1,976 & 64 \\
\hline 6 & Veterinary Quarterly & 1,603 & 9 \\
\hline 7 & $\begin{array}{l}\text { Transboundary and Emerging } \\
\text { Disease }\end{array}$ & 1,572 & 126 \\
\hline 8 & PLOS One & 1,386 & 57 \\
\hline 9 & Journal of Virological Methods & 1,152 & 51 \\
\hline 10 & $\begin{array}{l}\text { American Journal of Veterinary } \\
\text { Research }\end{array}$ & 992 & 35 \\
\hline 11 & Virus Research & 841 & 42 \\
\hline 12 & Preventive Veterinary Medicine & 821 & 51 \\
\hline 13 & Emerging Infectious Diseases & 753 & 13 \\
\hline 14 & Virus Genes & 722 & 27 \\
\hline 15 & Veterinary Research & 713 & 28 \\
\hline 16 & $\begin{array}{l}\text { Veterinary Immunology and } \\
\text { Immunopathology }\end{array}$ & 614 & 25 \\
\hline 17 & Journal of Clinical Microbiology & 597 & 24 \\
\hline 18 & Vaccine & 508 & 17 \\
\hline 19 & Antiviral Research & 493 & 12 \\
\hline 20 & Scientific Reports & 464 & 13 \\
\hline
\end{tabular}

Source: Author's computation and elaboration with the WOS data. of citation of papers published in journal was 6,275. Therefore, this journal is considered the most influential journal. The second place was taken by Virology, in which 73 papers were published with a total number of time of citation of 2,905 times. The fact that the number of papers published is small but the number of times of citation is large, is a proof that the papers are influential in the field of ASF, and are recognized as major studies among scholars. In particular, the Veterinary Quarterly published a total of 9 papers, but the papers were cited 1,603 times. It can be seen that the influence of this journal is very large compared to the number of papers published.

\section{Leading countries and institutes in the ASF}

Top 20 institutions that published the largest numbers of papers in ASF-related fields are listed in Table 5. BBSRC in the UK took the first place, and SCIC in Spain took the second place. In particular, institutions in the UK and Spain took the first to fifth places, and Euro-

Table 5. The top 20 most knowledge productive institute

\begin{tabular}{|c|c|c|c|c|}
\hline Rank & Institute & Country & Documents & Ratio (\%) \\
\hline 1 & Biotechnology and Biological Sciences Research Council (BBSRC) & UK & 210 & 11.44 \\
\hline 2 & Consejo Superior de Investigaciones Cientificas (CSIC) & Spain & 205 & 11.17 \\
\hline 3 & Pirbright Institute & UK & 199 & 10.84 \\
\hline 4 & UK Research Innovation (UKRI) & UK & 191 & 10.41 \\
\hline 5 & Autonomous University of Madrid & Spain & 163 & 8.88 \\
\hline 6 & United States Department of Agriculture (USDA) & USA & 136 & 7.41 \\
\hline 7 & Instituto Nacional Investigacion Tecnologia Agraria Alimentaria (INIA) & Spain & 107 & 5.83 \\
\hline 8 & Csic centro de Biologia Molecular severo ochoa (CBM) & Spain & 82 & 4.47 \\
\hline 9 & Friedrich Loeffler Institute & Germany & 68 & 3.71 \\
\hline 10 & Complutense University of Madrid & Spain & 59 & 3.22 \\
\hline 11 & Kansas State University & USA & 57 & 3.11 \\
\hline 12 & Chinese Academy of Agricultural Sciences & China & 55 & 3.00 \\
\hline 13 & Universidade de Lisboa & Portugal & 52 & 2.83 \\
\hline 14 & French Agricultural Research Organization (CIRAD) & France & 46 & 2.51 \\
\hline 14 & University of Pretoria & South Africa & 46 & 2.51 \\
\hline 16 & Universidad de Cordoba & Spain & 44 & 2.40 \\
\hline 17 & Science for Humanity's Greatest Challenges (CGIAR) & France & 41 & 2.23 \\
\hline 17 & International Livestock Research Institute (ILRI) & Kenya & 41 & 2.23 \\
\hline 19 & Iowa State University & USA & 39 & 2.13 \\
\hline 20 & Harbin Veterinary Research Institute (CAAS) & China & 37 & 2.02 \\
\hline
\end{tabular}

Source: Author's computation and elaboration with the WOS data. 
pean countries account for a large portion of the entire institutions. It can be seen that European countries are actively conducting ASF-related studies.

\section{The collaboration network between countries and} institutes

A list of top 20 countries that are leading cooperation among countries are follows.

- Cluster 1 (colored in green): Centering on Spain, European countries such as the UK, Germany, Italy, Denmark, Poland, the Netherlands, and Russia are cooperating in research.

- Cluster 2 (colored in red): Centering on the US, China, France, Canada, Belgium, Switzerland, Thailand, Japan, Vietnam, and Korea are cooperating in research.

- Cluster 3 (colored in blue): African countries and some European countries such as Australia, Kenya, Uganda, South Africa, and Sweden are cooperating in research.

The cooperation structure of the top 20 countries leading the cooperation among countries is visualized in Fig. 3. Spain is the most actively leading ASF-related research cooperation. In addition, the United States,
Britain, China, Germany and France are actively cooperating.

\section{The main keywords and thematic analysis}

Total link strength refers to the frequency of co-occurrence with others and it was mainly concentrated on the top 20 major keywords. Again, ASF and ASFV, which are the major keywords, occurred the most frequently followed by Pig and PRRSV and Wild boar, which mediates ASF, occurred quite frequently. In addition, keywords related to the monitoring of disease spread such as Epidemiology, Surveillance, and Transmission appeared frequently.

Author's keyword networks and clusters using VOSviewer are visualized in Fig. 4.

- Cluster 1 (colored in blue): ASFV forms the largest core, and centering on it, there are other keywords such as antiviral, control, DNA replication, Gene expression, Ornithodoros erraticus, Ornithodoros moubata, porcine epidemic diarrhea virus (PEDV), Proteome, RNA-seq, soft tick, and ubiquitin. Keywords for swine-infectious viruses and proteins such as protein and gene expression and antiviral were dominant.

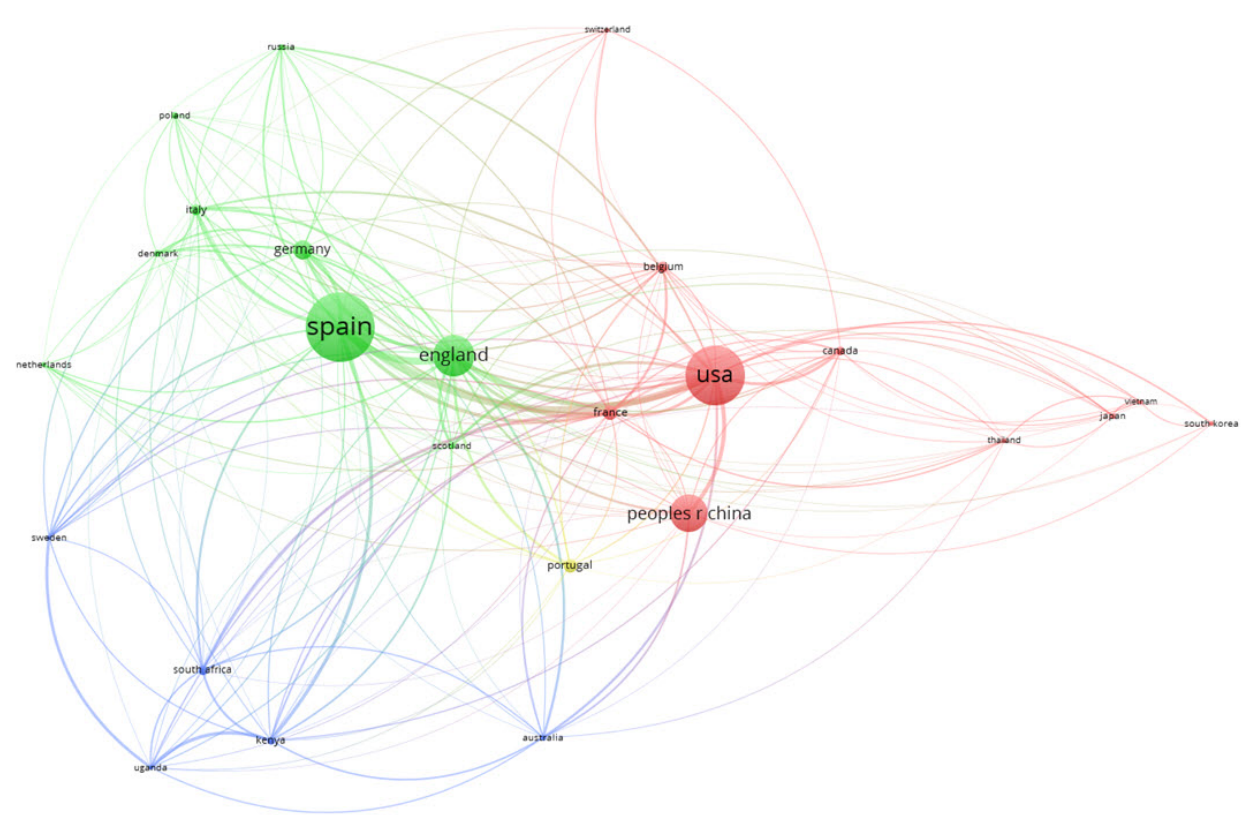

Fig. 3. Visual networks of global research collaboration. *Source: Authors' elaboration using VOSviewer software. 


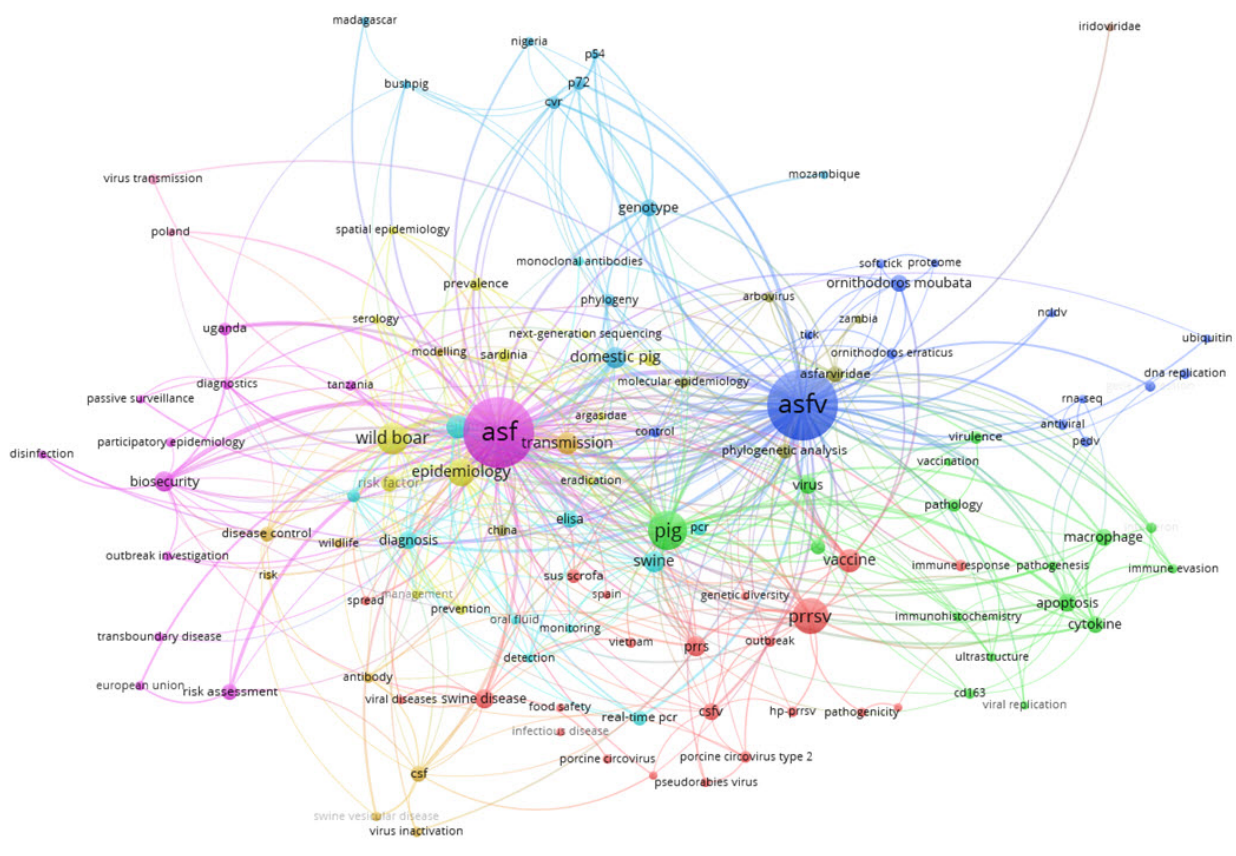

Fig. 4. Keyword network map and cluster. *Source: Authors' elaboration using VOSviewer software.
- Cluster 2 (colored in pink): African swine fever virus (ASF) forms the largest core, and there are other keywords such as Biosecurity, Diagnostics, Disinfection, European union, Outbreak investigation, Participatory epidemiology, Passive surveillance, Risk assessment, Transboundary disease, Tanzania, Uganda. Keywords related to coping and quarantine in relation to pig diseases are dominant because there are many keywords related to security, diagnosis, and investigation.

- Cluster 3 (colored in red): Porcine reproductive and respiratory syndrome virus (prrsv) form the largest core, and there are other keywords such as vaccine, porcine reproductive and respiratory syndrome virus (prrs), classical swine fever virus (csfv), swine disease, sus scrofa, viral disease, Vietnam, and Spain. Many keywords related to various swine diseases appeared, and it can be seen that there are many keywords for various swine diseases and lesions related to ASF.

- Cluster 4 (colored in green): Pig forms the largest core, and there are other keywords such as porcine, apoptosis, cytokine, macrophage, virus, immune evasion, pathology, virulence, and ultrastructure. There are many keywords for immunity to toxicity, defense against pathogens and infections, and related proteins.

- Cluster 5 (colored in yellow): Wild boar forms the largest core, and other keywords include Epidemiology, Argasidae, Eradication, Ornithodoros, Prevalence, Sardinia, and Serology. Keywords for group infection, transmission and prevalence, serum related to epidemiological investigation, and ticks involved in transmission are major.

- Cluster 6 (colored in skyblue): Surveillance forms the largest core, and other keywords include diagnosis, real-time PCR, elisa, monitoring, and monoclonal antibodies. Keywords for protein analysis and diagnosis, observation, and antibodies are major.

Also, Keywords changed by period are visualized in Fig. 5. More bluish colors indicate keywords that appeared relatively more often in the past, and more reddish colors indicate keywords that appeared more recently. The list of keywords is organized by period in Table 6 . The entire period was divided into the $1^{\text {st }}$ period, which is $1970 \sim 1990$, the $2^{\text {nd }}$ period, which is $1991 \sim$ 2010 , and the $3^{\text {rd }}$ period, which is 2011 2020.

- 1 st period: Keywords directly related to the occurrence, prevention, and diagnosis of ASF such as 


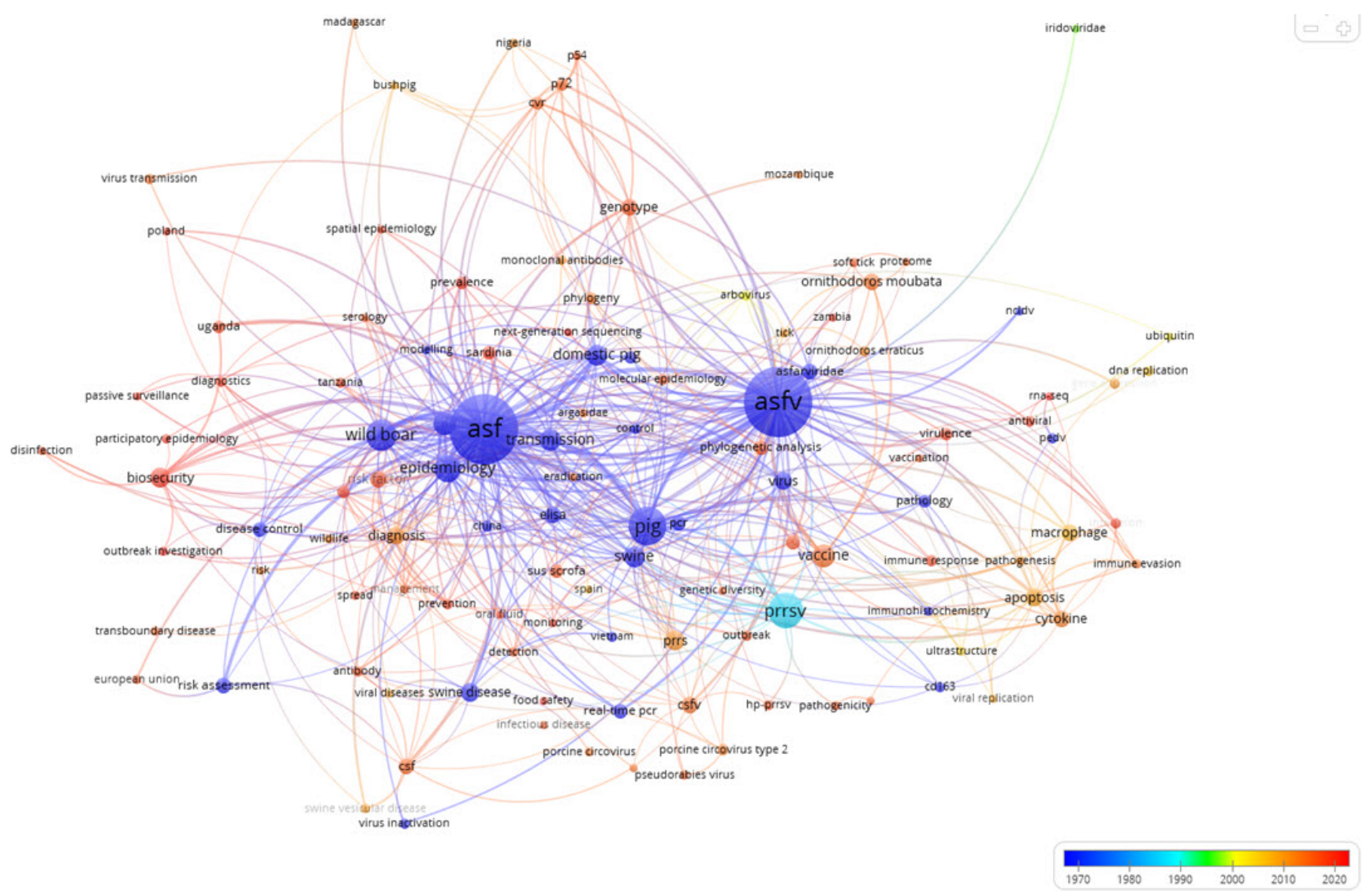

Fig. 5. Keywords network according to average publication year.

Table 6. Distribution of keywords according to average publication year

\begin{tabular}{|c|c|}
\hline Period & Keyword \\
\hline $1970 \sim 1990$ (1st) & $\begin{array}{l}\text { ASFV, ASF, wild boar, epidemiology, pig, swine, transmission, disease control, risk assessment, swine } \\
\text { disease, virus inactivation, real-time PCR, Vietnam, China, immunohistochemistry, pathology }\end{array}$ \\
\hline $1991 \sim 2010$ (2nd) & $\begin{array}{l}\text { PRRSV, PRRS, CSFV, pathogenicity, apoptosis, cytokine, macrophage, immune evasion, arbovirus, tick, } \\
\text { gene expression, interferon, monoclonal antibodies, Iridoviridae, diagnosis, ultrastructure, DNA replication, } \\
\text { molecular epidemiology, virus transmission, Tanzania, Spain, Mozambique }\end{array}$ \\
\hline $2011 \sim 2020$ (3rd) & $\begin{array}{l}\text { Antibodies, diagnostics, CSFV, CSF, detection, oral fluid, biosecurity, disinfection, participator epidemiology, } \\
\text { outbreak investigation, Argasidae, virulence, risk factor, prevention, transboundary disease, Sus scrofa, } \\
\text { genotype, passive surveillance, interferon, Poland, Uganda, Sardinia, European Union }\end{array}$ \\
\hline
\end{tabular}

Source: Author's elaboration using VOSviewer software and WOS data.

pigs, transmission, risk assessment, virus inactivation, real-time PCR, and immunohistochemistry are dominant. It can be seen that many studies related to the diagnosis of ASF disease were conducted in the early days.

- 2nd period: Studies on a wide range of pig disease studies to ASF, such as prrsv and csfv, were actively conducted and studies on response to transmission, causes of the outbreak of diseases, the development and progress of lesions, and virus spreads were mainly conducted.

- 3rd period: It can be seen that many studies related to ASF-related antibody, diagnosis, epidemiology to respond to outbreak and transmission, crossborder transmission, and monitoring were mainly conducted. 
Table 7. Research main summary

Framework

\begin{tabular}{ll}
\hline Trend of & - First study production in 1970 \\
increases in & - Significant increase in 1992 (19 pieces $->41$ pieces) \\
papers & - Decreases since 2000 (47 pieces - $>24$ pieces) \\
& - Increase again in 2015 and explosive increase in 2020 \\
Trend of & - Active research cooperation among European countries such as the UK, Germany, Italy, and Denmark centering on Spain \\
cooperation & - Research cooperation was led by China, France, Thailand, Japan, Vietnam, and Korea centering on the United States \\
Keyword & - 1st: ASF outbreak, prevention, and diagnosis such as risk assessment, real-time PCR, immunohistochemistry, etc. \\
changes by & - 2nd: Extensive pig disease studies related to ASF such as PRRSV, CSFV, and the occurrence of lesions and virus \\
time & propagation \\
& - 3rd: Antibody and diagnosis, outbreak, contagion response epidemiology, cross-border transmission, and disease \\
& monitoring
\end{tabular}

\section{DISCUSSION}

In this study, the global knowledge structure and research cooperation network of ASF research were analyzed. The major contents through which the knowledge structure of ASF in the field of pig disease studies was understood are the trend of increases of papers, the cooperative structure between countries, the top leading countries, and changes in keywords by period. The research is summarized in Table 7.

Centering on the results derived in this study, implications for the activation of studies in the field of ASF can be presented as follows.

First, given that the first occurrence was in 1920, there are not so many studies related to ASF. After the first three papers were published in the 1970s, 10 to 20 papers have been steadily produced every year in the early days. In 1992, 41 papers were produced showing an increase by more than two times compared to the previous year when 19 papers were produced. However, it can be seen that in the 2000s, research production decreased again. More than 50 papers were produced in 2011, and more than 100 papers were published only after 2017. The foregoing is a proof that relatively not many studies are conducted on ASF in the field of pig disease studies. After occurring for the first time in $\mathrm{Ke}^{-}$ nya in 1921, ASF has been steadily occurring in many countries in sub-Africa, and except for some countries such as Spain, it began to occur massively in Europe and Asia after 1995 (Sánchez-Vizcaíno et al, 2012; Normile, 2019). Therefore, it can be judged that the US, European and Asian countries have been passive in related studies.

Second, since ASF has been frequently occurring in China, parts of Asia, and South Korea recently, studies on ASF are necessary. Among the countries that are leading research cooperation among countries, South Korea ranks $17^{\text {th }}$, with a total of 26 published papers and a small number of times of citation (influence). In general, South Korea lacks paper production at present, and cooperation between countries is being made with certain countries or is lacking. In particular, South Korea is a neighboring country to China, which accounts for $60 \%$ of the world's pig industry. By April 22, 2019, 129 cases of ASF occurred in China and a total of 1.02 million pigs were destroyed (Wang et al, 2020). Therefore, the importance of ASF research increased in South Korea too. Active research activities are required in relation to rapid diagnosis, effective prevention, causes, and prediction are required along with quarantine activities for ASF, which is spreading rapidly through wild boars across borders. To that end, research cooperation with major countries such as Spain, the United States, and China will be important.

Third, according to keyword network analysis, the main keywords for ASF are protein, gene expression, diagnosis and security, defense against pathogen infection, epidemiological investigation, various pig diseases 
and lesions such as PRRSV and CSF, and immunity (Neser et al, 1986). Most of the journals where papers are published are those in fields related to pathology and veterinary science. In order to further strengthen the diversity of themes or the connection diversity of themes, interdisciplinary studies across diverse fields connected to management agendas such as promising and rapid diagnosis to prevent transmission, related technologies and social issues, and economic ripple effects are necessary. As ASF is a pig disease that occurred in the early 1900s, many accumulated knowledge systems have already been stabilized for pathological diagnosis, mutation, and transmission. However, the rapid propagation speed, high mortality rate, policy costs for eradication of ASF, and the astronomical social and economic losses in the event of occurrence are very large. In the case of Spain, it took about 36 years from the outbreak of ASF in 1960 to complete eradication in 1995 (Cwynar et al, 2019). Given that the only way is stamping out, the social cost should be enormous. Studies related to diverse areas are necessary such as infection monitoring, influx diagnosis, and outbreak investigation technology grafted with ICT technology, antibody and protein-related studies for vaccine development, methods for advancement of quarantine and epidemiological investigations, environmental concerns about the killing method in the event of an outbreak, economic ripples in the event of outbreak, social scientific approaches, such as policy devices for continuous monitoring, and animal welfare for herd immunity and antibodies.

Fourth, the major academic contribution of this study is the presentation of the direction of South Korean ASF research through knowledge structure analysis. The production of research, the impact of research, cooperation between countries for research, and changes in research themes can be visually compared and the situations of changes in research keywords by year (trending) can be identified. Through the foregoing, the level and development direction of research in the field of ASF in South Korea can be predicted.

\section{Limitations}

Not only quantitative analysis of ASF research production but also the analysis of the qualitative level of research production through analyses of citation degrees and SCI by journal are additionally required. In this study, the research target field was limited to 'ASF' in order to intensively analyze the knowledge structure of ASF. However, expanding the keywords to divers ones in the field of pig disease studies or in the field of social science such as business administration and economics will be useful in that animal infections should be approached from the viewpoint of integrated governance aiming at publicness. Legal systems and policies, government regulations, the necessity of vaccine development, comparison of benefits versus development costs, the effectiveness, and research into issues in the field of social science, and production status analysis should be approached diversely through follow-up studies.

\section{ACKNOWLEDGEMENTS}

This work was supported by Korea Institute of Planning and Evaluation for Technology in Food, Agriculture and Forestry (IPET) through Animal Disease Management Technology Development Program, funded by Ministry of Agriculture, Food and Rural Affairs (MAFRA) (No. 320067-02-1-CG000).

\section{CONFLICT OF INTEREST}

No potential conflict of interest relevant to this article was reported.

\section{ORCID}

Jee-Sun Oh, https://orcid.org/0000-0002-3477-0711

Ho-Seong Cho, https://orcid.org/0000-0001-7443-167X

Yeonsu Oh, https://orcid.org/0000-0001-5743-5396 


\section{REFERENCES}

Andraud M, Rose N. 2020. Modelling infectious viral diseases in swine populations: a state of the art. Porc Health Manag 6: 1-12.

Brown AA, Penrith ML, Fasina FO, Beltran-Alcrudo D. 2018. The African swine fever epidemic in West Africa, 1996-2002. Transbound Emerg Dis 65: 6476.

Chenais E, Boqvist S, Emanuelson U, Von Brömssen C, Ouma E, Aliro T, Masembe C, Ståhl K, SternbergLewerin S. 2017. Quantitative assessment of social and economic impact of African swine fever outbreaks in northern Uganda. Prev Vet Med 144: 134148.

Costard S, Wieland B, de Glanville W, Jori F, Rowlands R, Vosloo W, Roger F, Pfeiffer DU, Dixon LK. 2009. African swine fever: how can global spread be prevented?. Philos Trans R Soc Lond B Biol Sci 364: 2683-2696.

Cwynar P, Stojkov J, Wlazlak K. 2019. African swine fever status in Europe. Viruses 11: 310.

Díaz I, Cortey M, Olvera À, Segalés J. 2016. Use of HIndex and other bibliometric indicators to evaluate research productivity outcome on swine diseases. PLoS One 11: e0149690.

Dixon LK, Stahl K, Jori F, Vial L, Pfeiffer Du. 2020. African swine fever epidemiology and control. Annu Rev Anim Biosci 8: 221-246.

Dixon LK, Sun H, Roberts H. 2019. African swine fever. Antiviral Res 165: 34-41.

Fernández-Carrión E, Ivorra B, Martínez-López B, Ramos AM, Sánchez-Vizcaíno JM. 2016. Implementation and validation of an economic module in the Be-FAST model to predict costs generated by livestock disease epidemics: Application to classical swine fever epidemics in Spain. Prev Vet Med 126: 66-73.

Gallardo C, Fernández-Pinero J, Pelayo V, Gazaev I, Markowska-Daniel I, Pridotkas G, Nieto R, Fernández-Pacheco P, Bokhan S, Nevolko O, Drozhzhe Z,
Pérez C, Soler A, Kolvasov D, Arias M. 2014. Genetic variation among African swine fever genotype II viruses, eastern and central Europe. Emerg Infect Dis 20: $1544-1547$.

Gallardo MC, de la Torre Reoyo A, Fernández-Pinero J, Iglesias I, Muñoz MJ, Arias ML. 2015. African swine fever: a global view of the current challenge. Porc Health Manag 1: 21.

Ge S, Li J, Fan X, Liu F, Li L, Wang Q, Ren W, Bao J, Liu C, Wang H, Liu Y, Zhang Y, Xu T, Wu X, Wang Z. 2018. Molecular characterization of African swine fever virus, China, 2018. Emerg Infect Dis 24: 21312133.

Gogin A, Gerasimov V, Malogolovkin A, Kolbasov D. 2013. African swine fever in the North Caucasus region and the Russian Federation in years 20072012. Virus Res 173: 198-203.

Guinat C, Vergne T, Jurado-Diaz C, Sánchez-Vizcaíno JM, Dixon L, Pfeiffer DU. 2017. Effectiveness and practicality of control strategies for African swine fever: what do we really know?. Vet Rec 180: 97.

Jurado C, Mur L, Aguirreburualde MSP, CadenasFernández E, Martínez-López B, Sánchez-Vizcaíno JM, Perez A. 2019. Risk of African swine fever virus introduction into the United States through smuggling of pork in air passenger luggage. Sci Rep 9: 14423.

Kim SH, Kim J, Son K, Choi Y, Jeong HS, Kim YK, Park JE, Hong YJ, Lee SI, Wang SJ, Lee HS, Kim WM, Jheong WH. 2020. Wild boar harbouring African swine fever virus in the demilitarized zone in South Korea, 2019. Emerg Microbes Infect 9: 628-630.

Kim Y, Park B, Kang H. 2021. Control measures to African swine fever outbreak: active response in South Korea, preparation for the future, and cooperation. J Vet Sci 22: e13.

Kolbasov D, Titov I, Tsybanov S, Gogin A, Malogolovkin A. 2018. African swine fever virus, Siberia, Russia, 2017. Emerg Infect Dis 24: 796-798.

Le VP, Yoon SW, Kwon HM, Trinh TB, Nguyen TL, Bui TT, Oh J, Kim JB, Cheong KM, Van Tuyen N, Bae E, 
Vu TT, Yeom M, Na W, Song D. 2019. Outbreak of African swine fever, Vietnam, 2019. Emerg Infect Dis 25: $1433-1435$.

Le VP, Yoon SW, Kwon HM, Trinh TB, Nguyen TL, Bui TT, Oh J, Kim JB, Cheong KM, Van Tuyen N, Bae E, Vu TT, Yeom M, Na W, Song D. 2019. Outbreak of African swine fever, Vietnam, 2019. Emerg Infect Dis 25: 1433-1435.

Malogolovkin A, Burmakina G, Titov I, Sereda A, Gogin A, Baryshnikova E, Kolbasov D. 2015. Comparative analysis of African swine fever virus genotypes and serogroups. Emerging Infectious Diseases 21(2): 312.

Neser JA, Phillips T, Gainaru MD, Coetzee T, Thomson GR. 1986. African swine fever. I. Morphological changes and virus replication in blood platelets of pigs infected with virulent haemadsorbing and non-haemadsorbing isolates. Onderstepoort J Vet Res 53: 133-141.

Normile D. 2019. African swine fever marches across much of Asia. Science 364: 617-618.

Oganesyan AS, Petrova ON, Korennoy FI, Bardina NS, Gogin AE, Dudnikov SA. 2013. African swine fever in the Russian Federation: spatio-temporal analysis and epidemiological overview. Virus Res 173: 204211.

Penrith M, Vosloo W, Jori F, Bastos AD. 2013. African swine fever virus eradication in Africa. Virus Res 173: 228-246.

Sánchez-Cordón PJ, Montoya M, Reis AL, Dixon LK. 2018. African swine fever: A re-emerging viral disease threatening the global pig industry. Vet J 233: 41-48.

Sanna G, Dei Giudici S, Bacciu D, Angioi PP, Giammarioli M, De Mia GM, Oggiano A. 2017. Improved strategy for molecular characterization of African swine fever viruses from Sardinia, based on analysis of $\mathrm{p} 30, \mathrm{CD} 2 \mathrm{~V}$ and $\mathrm{I73R} / \mathrm{I} 329 \mathrm{~L}$ variable regions. Transbound Emerg Dis 64: 1280-1286.

Serenko A, Bontis N, Booker L, Sadeddin K, Hardie T. 2010. A scientometric analysis of knowledge man- agement and intellectual capital academic literature (1994-2008). J Knowl Manag 14: 3-23.

Sinclair M, Zhang Y, Descovich K, Phillips CJ. 2020. Farm Animal Welfare Science in China-A bibliometric review of Chinese literature. Animals 10: 540.

Śmietanka K, Wozniakowski G, Kozak E, Niemczuk K, Fraczyk M, Bocian L, Kowalczyk A, Pejsak Z. 2016. African swine fever epidemic, Poland, 2014-2015. Emerg Infect Dis 22: 1201-1207.

Smith KG, Collins CJ, Clark KD. 2005. Existing knowledge, knowledge creation capability, and the rate of new product introduction in high-technology firms. Acad Manage J 48: 346-357.

Subramanyam K. 1983. Bibliometric studies of research collaboration: A review. J Inf Sci 6: 33-38.

Tian D. 2020. Bibliometric analysis of pathogenic organisms. Biosafety and Health. 2: 95-103.

Tian X, von Cramon-Taubadel S. 2020. Economic consequences of African swine fever. Nat Food 1: 196197.

van Eck NJ, Waltman L. 2010. Software survey: VOSviewer, a computer program for bibliometric mapping. Scientometrics 84: 523-538.

Wang A, Jia R, Liu Y, Zhou J, Qi Y, Chen Y, Liu D, Zhao J, Shi H, Zhang J, Zhang G. 2020. Development of a novel quantitative real-time PCR assay with lyophilized powder reagent to detect African swine fever virus in blood samples of domestic pigs in China. Transbound Emerg Dis 67: 284-297.

Wang T, Sun Y, Qiu HJ. 2018. African swine fever: an unprecedented disaster and challenge to China. Infect Dis Poverty 7: 111.

Woonwong Y, Do Tien D, Thanawongnuwech R. 2020. The future of the pig industry after the introduction of African swine fever into Asia. Anim Front 10: 30-37.

Yan E, Ding Y. 2012. Scholarly network similarities: How bibliographic coupling networks, citation networks, cocitation networks, topical networks, coauthorship networks, and coword networks relate 
to each other. J Assoc Inf Sci 63: 1313-1326.

Yoo D, Kim H, Lee JY, Yoo HS. 2020. African swine fever: Etiology, epidemiological status in Korea, and perspective on control. J Vet Sci 21: e38.
Zhou X, Li N, Luo Y, Liu YE, Miao F, Chen T, Zhang S, Chao P, Li X, Tian K, Qiu HJ, Hu R. 2018. Emergence of African swine fever in China, 2018. Transbound Emerg Dis 65: 1482-1484. 